\title{
Comparison of Preparation Methods of Copper Based PGM- Free Diesel-Soot Oxidation Catalysts
}

\author{
R. Prasad *, V.R. Bella \\ Department of Chemical Engineering \& Technology, Institute of Technology \\ Banaras Hindu University, Varanasi 221005, India
}

Received: 27th June 2010, Revised: 7th August 2010; Accepted: 13rd October 2010

\begin{abstract}
$\mathrm{CuO}-\mathrm{CeO}_{2}$ systems have been proposed as a promising catalyst for low temperature diesel-soot oxidation. $\mathrm{CuO}-\mathrm{CeO}_{2}$ catalysts prepared by various methods were examined for air oxidation of the soot in a semi batch tubular flow reactor. The air oxidation of soot was carried out under tight contact with soot/catalyst ratio of $1 / 10$. Air flow rate was $150 \mathrm{ml} / \mathrm{min}$, soot-catalyst mixture was $110 \mathrm{mg}$, heating rate was $5{ }^{\circ} \mathrm{C} / \mathrm{min}$. Prepared catalysts were calcined at $500{ }^{\circ} \mathrm{C}$ and their stability was examined by further heating to $800{ }^{\circ} \mathrm{C}$ for 4 hours. It was found that the selectivity of all the catalysts was nearly $100 \%$ to $\mathrm{CO}_{2}$ production. It was observed that the activity and stability of the catalysts greatly influenced by the preparation methods. The strong interaction between $\mathrm{CuO}$ and $\mathrm{CeO}_{2}$ is closely related to the preparation route that plays a crucial role in the soot oxidation over the $\mathrm{CuO}-\mathrm{CeO}_{2}$ catalysts. The ranking order of the preparation methods of the catalysts in the soot oxidation performance is as follows: sol-gel $>$ urea nitrate combustion $>$ Urea gelation method > thermal decomposition > co-precipitation . Copyright (C) 2011 BCREC UNDIP. All rights reserved.
\end{abstract}

Keywords: Copper-ceria; Diesel soot; Catalytic combustion; Soot oxidation catalyst; Preparation methods

\section{Introduction}

The incomplete combustion that occurs in diesel engines leads to enormous emissions of atmospheric pollutants as soot particles consisting of agglomerates of carbon nuclei and hydrocarbons, $\mathrm{SO}_{3}$ or sulfuric acid, and have been identified as hazardous to human health and environment [1]. One of the solutions to avoid the emission of soot produced by diesel vehicles is to trap the particles on a diesel particulate filters (DPFs) and burn soot periodically to prevent a pressure increase in the exhaust line [1,2]. The major problem of trapped soot removal is the too high onset temperature $\left(>500{ }^{0} \mathrm{C}\right)$ for soot combustion to create aspontaneous and self-propagating regeneration of DPFs [1]. For spontaneous regeneration under typical engine operating conditions, oxidation catalysts-based DPFs are required to enhance the soot combustion at diesel exhaust gas temperatures $\left(250-400{ }^{\circ} \mathrm{C}\right)$. The catalysts should promote soot catalytic combustion at rather low temperature and display high stability, excellent catalytic activity and durability under practical working conditions [3-4].

Many kinds of catalysts have been investigated for the soot combustion, including low melting point compounds [5], platinum group metals (PGM) [6-8], perovskite type oxides [9-10], spinel

\footnotetext{
* Corresponding Author.

E-mail: rprasad.che@itbhu.ac.in (R. Prasad) Tel.: +91 542 2367323, fax: +91 5422368092
} 
type oxides [11], rare earth metal oxides, and mixed transient metal oxides [12-14]. It is well known that activity and selectivity of $\mathrm{CeO}_{2}$-based catalysts are greatly enhanced not only by noble metals, but also by base metals, particularly copper [15]. A PGM coated DPF has been presented as an efficient after-treatment system [16-17]. But in recent years, considering the high cost, limited availability of the noble metals and their instability with impurities, more attention has been focused on the base metal catalysts [1819]. In this context PGM-free, $\mathrm{CuO}-\mathrm{CeO}_{2}$ catalysts are expected to be a good alternative for diesel soot oxidation [15].

$\mathrm{CeO}_{2}$ is a crucial component in diesel soot oxidation catalyst [20-21]. The main properties of cerium oxides for oxidation reactions are: (1) the excellent oxygen storage capacity (OSC) provided by the redox couple $\mathrm{Ce}_{4+} / \mathrm{Ce}_{3+}$, making active oxygen available for the acceleration of soot oxidation [20,22]; (2) structural enhancement of the metal dispersion; and (3) improvement of the thermal stability of supports. The active oxygen also affects nitrate storage capacity for simultaneous deSoot and deNOx [23]. There exists some kind of synergistic redox effect of copper [23] and cerium in the soot oxidation.

It is a long recognized fact that the properties of the catalysts often depend on their preparation methods. The dispersion and size distribution of metal crystallites, their spatial distribution on the support, the homogeneity of components in a multi-component catalyst, the porosity, surface area, and pore size distribution are the examples of sensitive functions. This sensitivity is with respect to the precursors used and the treatment temperature and atmosphere, as well as other preparation variables, which in turn strongly affect the catalyst activity. In recent years, there has been a significant progress towards understanding the relationship between the preparation method and the final properties of catalysts and catalytic supports. Several methods [24] have been used for the preparation of the versatile $\mathrm{CuO}-\mathrm{CeO}_{2}$ catalysts.

In spite of the more and more interest drawn on $\mathrm{CuO}-\mathrm{CeO}_{2}$ catalysts for soot oxidation, literatures on the selection of synthesis methods determining the physiochemical features or factors related to activity remain quite limited. Earlier works are limited to the optimization of the composition of the catalysts [20, 25]. Most recently, Fua et al. [19] prepared $\mathrm{CuO}-\mathrm{CeO} 2$ using two routes, co-precipitation $(\mathrm{CP})$ and citrate acid complex-combustion synthesis (CA) to correlate catalytic activity and the physiochemical features of the catalysts synthesized by the methods, CP and CA. When compared to $\mathrm{Cu}_{0.05} \mathrm{Ce}_{0.95} \mathrm{CP}$, the better reducibility and greater OSC, and active oxygen species of $\mathrm{Cu}_{0.05} \mathrm{Ce}_{0.95}$ - $\mathrm{CA}$ coincided with its better activity. They proposed a possible pathway of soot oxidation over $\mathrm{Cu}_{0.05} \mathrm{Ce}_{0.95}-\mathrm{CA}$, based on the relationship of the performance and the physicochemical features of catalysts, which pathway follows the mechanism associated with redox couple and oxygen spill over effect.

In the present investigation, the activity, selectivity and stability of $\mathrm{CuO}-\mathrm{CeO}_{2}$ catalysts prepared by 5 different methods have been evaluated in oxidation of diesel soot particulates to find out the best method of the catalyst preparation.

\section{Materials and Methods}

\subsection{Catalyst Preparation}

In this work copper-ceria catalysts were prepared by the following five methods:

(1) Thermal decomposition method,

(2) Co-ppt method,

(3) Urea-nitrate combustion method,

(4) Urea gelation (UGC) method, and

(5). Citric acid sol-gel method

\section{(1) Thermal decomposition method:}

The thermal decomposition method was the simplest of all other methods studied here. In this method copper nitrate $\mathrm{Cu}\left(\mathrm{NO}_{3}\right)_{2} .3 \mathrm{H}_{2} \mathrm{O}$ and cerium nitrate $\mathrm{Ce}\left(\mathrm{NO}_{3}\right)_{3} \cdot 6 \mathrm{H}_{2} \mathrm{O}$ in the molar ratio of $3 / 20$ were dissolved in distilled water followed by evaporation over steam bath, drying at $110{ }^{\circ} \mathrm{C}$ overnight in an oven. The received powders were submitted to decomposition at $300{ }^{\circ} \mathrm{C}$ for $1 \mathrm{~h}$ and calcination at $500{ }^{\circ} \mathrm{C}$ for $3 \mathrm{~h}$ in a muffle furnace. The powders were cooled to room temperature in the furnace to obtain the so-called fresh sample. Half of the sample was aged at $800{ }^{\circ} \mathrm{C}$ for $4 \mathrm{~h}$ in a furnace to obtain the aged sample.

\section{2) Co-precipitation method:}

In this method also the catalysts were prepared, with $\mathrm{Cu} /(\mathrm{Cu}+\mathrm{Ce})$ molar ratio equal to $3 / 20$. The nitrates of copper and cerium were dissolved in distilled water according to the required molar ratio. Co-precipitation of the components as oxalates was carried out by adding drop-wise oxalic acid solution (10\% excess). The precipitate was filtered and washed several times 
to free of nitrate ions. The precipitate was dried at $110{ }^{\circ} \mathrm{C}$ overnight in an oven. Rest of the steps of preparation was repeated as in the previous method to obtain the fresh as well as the aged samples.

\section{(3) Urea-nitrate combustion method}

Urea combustion with nitrates is an effective, single pot technique for the preparation of $\mathrm{CuO}$ $\mathrm{CeO}_{2}$ catalysts. In this work $\mathrm{CuO}-\mathrm{CeO}_{2}$ catalyst samples were prepared by Urea-nitrate combustion method as described by Avgouropoulos et al. [26]. The urea-nitrate combustion method was used for the synthesis of $\mathrm{CuO}-\mathrm{CeO}_{2}$ mixed oxide catalysts. Cerium nitrate, copper nitrate, and urea $\mathrm{CO}\left(\mathrm{NH}_{2}\right)_{2}$ were dissolved in a minimum volume of distilled water to obtain a transparent solution. The $\mathrm{Cu} /(\mathrm{Cu}+\mathrm{Ce})$ molar ratio was equal to $3 / 20$, while the urea/nitrate molar ratio was 2.38 . The blended solution was sufficiently mixed with the help of a magnetic stirrer at $80^{\circ} \mathrm{C}$ for a few minutes. The resulting viscous gel was introduced in an open muffle furnace, preheated at $500{ }^{\circ} \mathrm{C}$, in a fuming cupboard. The gel started boiling with frothing and foaming, and in a couple of minutes ignited spontaneously with rapid evolution of a large quantity of gases, yielding a foamy, voluminous powder. The powders were cooled to room temperature in the furnace to obtain the so-called fresh sample. Half of the sample was aged at 800 ${ }^{0} \mathrm{C}$ for $4 \mathrm{~h}$ in a furnace to obtain the aged sample.

\section{(4) Urea gelation (UG) method:}

$\mathrm{CuO}-\mathrm{CeO}_{2}$ was prepared by the urea gelation (UG) method as described elsewhere [27]. The preparation procedure consists of mixing the aqueous metal nitrate solutions with urea $\left(\mathrm{NH}_{2}\right.$ $\mathrm{CO}-\mathrm{NH}_{2}$ ); heating the solution to $100{ }^{\circ} \mathrm{C}$ under vigorous stirring over magnetic stirrer and addition of distilled water; boiling the resulting gel for $8 \mathrm{~h}$ at $100{ }^{\circ} \mathrm{C}$; filtering and washing the precipitate twice with distilled water at $50-70{ }^{\circ} \mathrm{C}$; drying the cake in a vacuum oven at $80-100{ }^{\circ} \mathrm{C}$ for over night; crushing the dried lump into smaller particles. Rest of the steps of preparation was repeated as in the previous methods to obtain the fresh as well as the aged samples.

\section{(5) Citric acid sol-gel method}

Catalyst samples, $\mathrm{CuO}-\mathrm{CeO}_{2}$ mixed oxides with $\mathrm{Cu} /(\mathrm{Cu}+\mathrm{Ce})$ molar ratio equal to $3 / 20$ was prepared by citric acid sol-gel method as described by Liang et al. [20]. The nitrates of copper and cerium were dissolved in distilled water according to the required molar ratio. Citric acid was added as the complexing agent with a 1.3:1 ratio of the acid to metal ions including $\mathrm{Ce}^{3+}$ and $\mathrm{Cu}^{2+}$. Appropriate polyglycol was followed with the weight of $10 \%$ citric acid added. The blended solution was thoroughly mixed with the help of a magnetic stirrer and heated at $80^{\circ} \mathrm{C}$ till transparent gel was formed. The resulting gel was dried at $110{ }^{\circ} \mathrm{C}$ overnight in an oven. Rest of the steps of preparation was repeated as in the previous method to obtain the fresh as well as the aged samples. Nomenclature of the catalysts prepared by different methods is given in table 1 .

\subsection{Catalyst characterization}

The particle size analysis of the samples were measured using the laser diffraction (HeliumNeon Laser, 5 Milliwat) based particle size analyser (ANKERSMID, CIS-50, U.S.A). Particle size Analysis data are given in table 2.

\subsection{Soot preparation}

The soot was prepared by partial combustion of commercial diesel obtained from Hindustan petroleum (HP) in a lamp with a limited supply of air [28-30] as shown Figure 1. The deposited soot on the inner walls of an inverted beaker was collected and then dried in an oven for overnight at $120^{\circ} \mathrm{C}$

\subsection{Bench scale semi-batch reactor}

The reactor described in reference [31] was used in the present studies as shown in Figure 2. A helical coil of glass tube in between the coaxial tubes, served as an air pre-heater. Thus the air was heated to the reaction temperature before entering the bed of soot-catalyst mixture kept in

Table 1. Nomenclature of the $\mathrm{CuO}-\mathrm{CeO}_{2}$ catalysts prepared by different methods

\begin{tabular}{|l|l|l|l|}
\hline Catal. & $\begin{array}{l}\text { Prepn. } \\
\text { method }\end{array}$ & $\begin{array}{l}\text { Cu-Ce- } \\
\text { Precursor }\end{array}$ & $\begin{array}{l}* \text { Calcn/ageing } \\
\text { temperature }\end{array}$ \\
\hline $\mathrm{A}_{1} / \mathrm{A}_{2}$ & Thermal & Nitrates & $500 / 800^{\circ} \mathrm{C}$ \\
\hline $\mathrm{B}_{1} / \mathrm{B}_{2}$ & $\mathrm{CO}-\mathrm{ppt}$ & Oxalates & $500 / 800^{\circ} \mathrm{C}$ \\
\hline $\mathrm{C}_{1} / \mathrm{C}_{2}$ & $\mathrm{UNC}$ & Nitrate & $500 / 800^{\circ} \mathrm{C}$ \\
\hline $\mathrm{D}_{1} / \mathrm{D}_{2}$ & $\mathrm{UG}$ & Nitrate & $500 / 800^{\circ} \mathrm{C}$ \\
\hline $\mathrm{E}_{1} / \mathrm{E}_{2}$ & Sol-gel & Nitrate & $500 / 800^{\circ} \mathrm{C}$ \\
\hline
\end{tabular}

*Suffixes 1 and 2 denote the calcination/ageing temperatures of the catalysts respectively. 
Table 2. Particle size analysis of $\mathrm{Cu}-\mathrm{Ce}(3 / 20$ molar) catalysts prepared by different methods

\begin{tabular}{llll}
\hline $\begin{array}{l}\text { Prepn. } \\
\text { method }\end{array}$ & Components & \multicolumn{2}{l}{ Mean particle size $(\boldsymbol{\mu m})$} \\
& & $\mathbf{5 0 0}{ }^{\circ} \mathbf{C}$ & $\mathbf{8 0 0}{ }^{\circ} \mathbf{C}$ \\
\hline Thermal & $\mathrm{Cu}-\mathrm{Ce}$ & $0.98\left(\mathrm{~A}_{1}\right)$ & $1.34\left(\mathrm{~A}_{2}\right)$ \\
Co-ppt & $\mathrm{Cu}-\mathrm{Ce}$ & $1.06\left(\mathrm{~B}_{1}\right)$ & $2.13\left(\mathrm{~B}_{2}\right)$ \\
UNC & $\mathrm{Cu}-\mathrm{Ce}$ & $1.02\left(\mathrm{C}_{1}\right)$ & $1.38\left(\mathrm{C}_{2}\right)$ \\
UG & $\mathrm{Cu}-\mathrm{Ce}$ & $1.22\left(\mathrm{D}_{1}\right)$ & $1.47\left(\mathrm{D}_{2}\right)$ \\
Sol-gel & $\mathrm{Cu}-\mathrm{Ce}$ & $0.93\left(\mathrm{E}_{1}\right)$ & $1.29\left(\mathrm{E}_{2}\right)$ \\
\hline
\end{tabular}

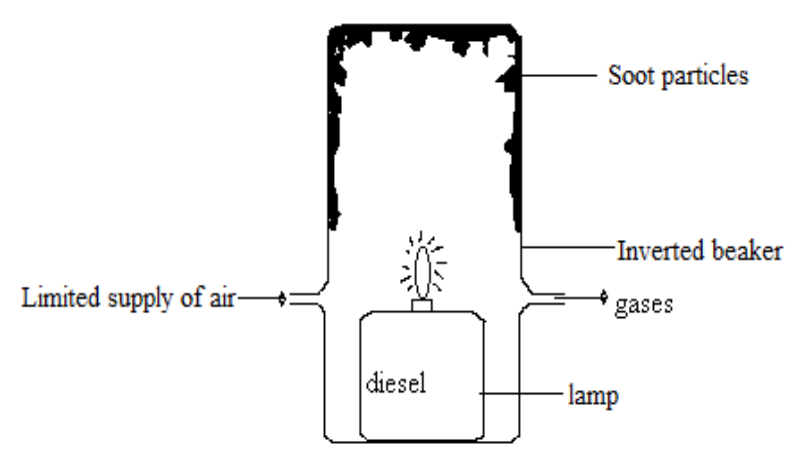

Figure1. Schematic diagram showing soot preparation

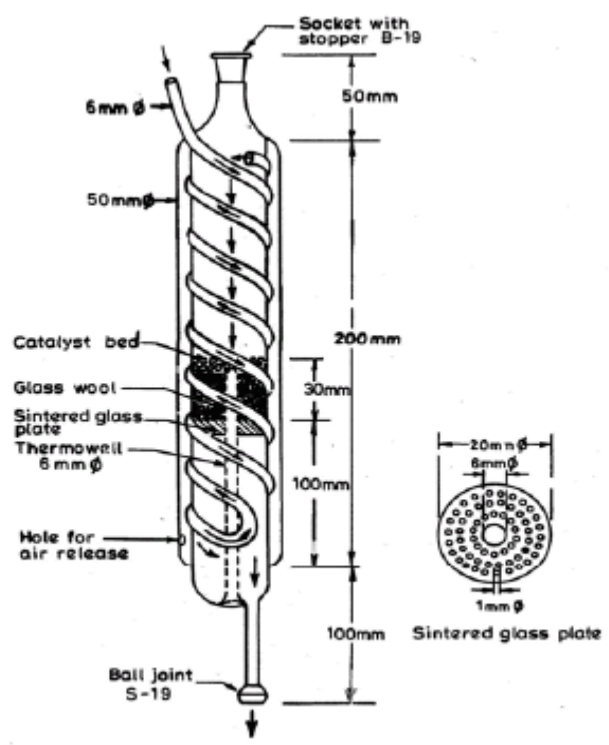

Figure 2. Schematic diagram of the reactor

the mid of the inner tube as shown in the figure. The attractive features of the versatile reactor are its compact nature and it can be used as a tubular flow reactor as well as a semi-batch reactor. Compactness of the reactor means the pre-heater and the fixed bed are merged together in a single unit.

\subsection{Experimental procedure}

The catalytic activity for oxidation of the soot was evaluated in the bench scale semi-batch reactor as described above. A known weight, 110 $\mathrm{mg}$ of the soot-catalyst mixture was taken in a $1 / 10$ weight ratio and packed the rector over glass wool. The soot-catalyst mixture were milled in an agate mortar for "tight contact" between soot and catalysts. The oxidation reaction was carried out in the temperature range from ambient to $550{ }^{\circ} \mathrm{C}$ at a heating rate of $5{ }^{\circ} \mathrm{C} \mathrm{min}^{-1}$. The inlet air free from $\mathrm{CO}_{2}$ was fed to the reactor at a flow rate of $150 \mathrm{ml} / \mathrm{min}$. The outlet gases were analyzed for $\mathrm{CO}$ and $\mathrm{CO}_{2}$ by an on-line gas chromatograph equipped with methaniser using a porapack Qcolumn and a FID detector. The chromatogram showed single peak of $\mathrm{CO}_{2}$ and practically concentration of $\mathrm{CO}$ in the product stream was nil with all the catalysts. The GC analysis is reported in terms of soot conversion.

\section{Results and Discussion}

\subsection{Effect of preparation methods on activity}

The catalytic activity of $\mathrm{CuO}-\mathrm{CeO}_{2}$ catalysts having same composition prepared by 5 different methods for diesel soot oxidation is shown in Figure 3. It is very clear from the figure that the catalyst prepared by sol-gel (E1) method presented the highest activity in comparison to the catalysts prepared following the other methods. The relatively lowest catalytic activity exhibited by the co-precipitation catalyst sample (B1) is most probably due to formation of bulk segregated $\mathrm{CuO}$ phase. The sample (E1) synthesized by sol-gel method exhibited the highest activity as this method offers better control over textural characteristics. It is evident from table 2 that the average particle size $(0.93$ $\mu \mathrm{m})$ of the catalyst (E1) is the smallest in comparision to the other samples. Being smallest particle size, catalyst E1 possesed largest surface area hence highest activity than other catalysts studied. In sol-gel method hydrophilic colloidal solutions are formed of micelles that remain separated because of electrical charges on their surfaces and in the surrounding solution. These charges create repelling forces which prohibit coagulation of the micelles. Such micelles are produced via chemical reactions of polymerization and poly-condensation. Thus, highly dispersed 


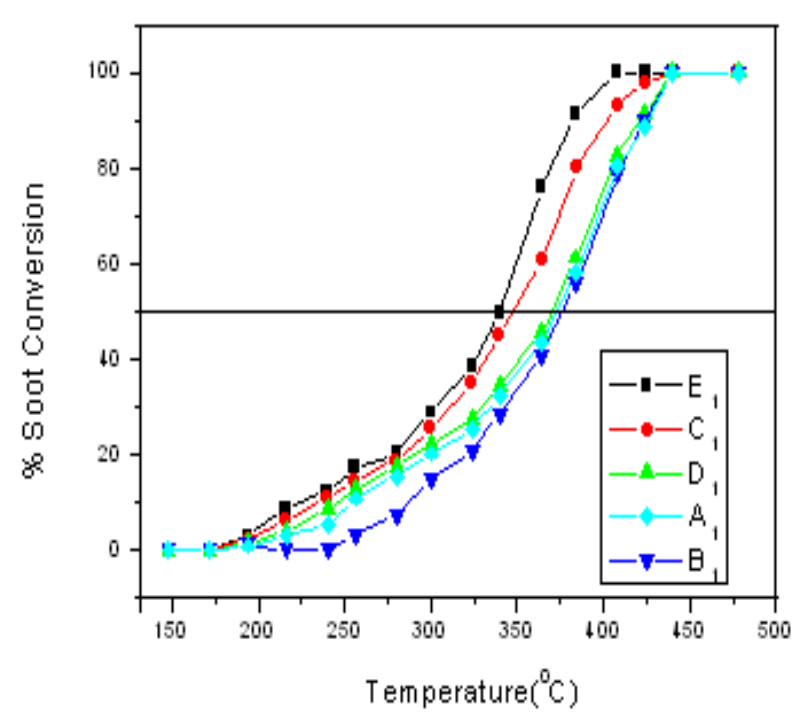

Figure 3. Effect of preparation methods of $\mathrm{Cu}-\mathrm{Ce}$ catalysts on activity for soot oxidation

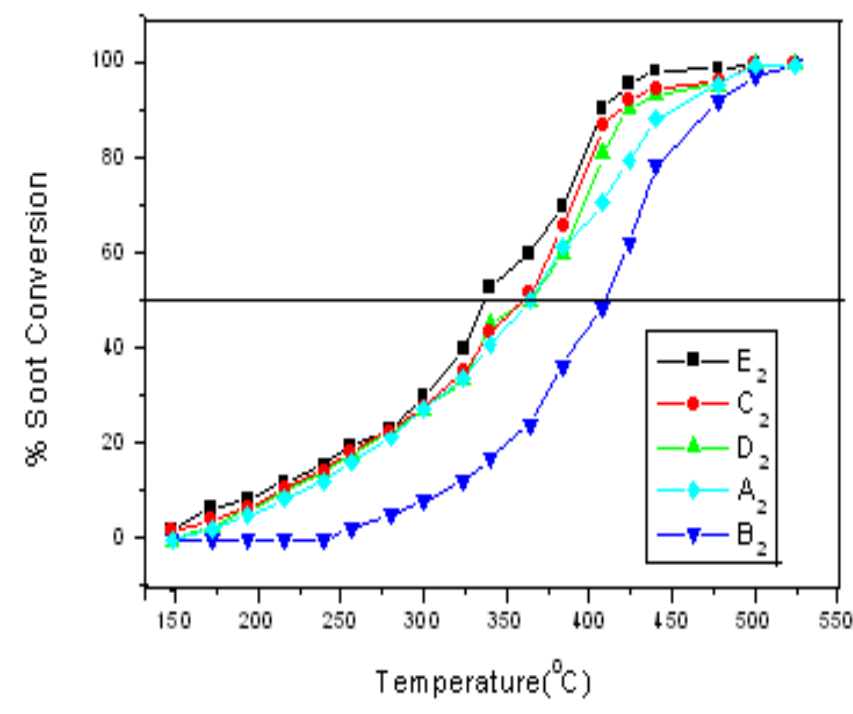

Figure 4. Effect of ageing on Cu-Ce catalysts at 800 ${ }^{0} \mathrm{C}$ for $4 \mathrm{~h}$ on soot oxidation

catalyst is resulted by sol-gel method.

It can be seen from the figure that $\mathrm{T} 1 / 2$ (temperature at $50 \%$ soot combustion) for catalysts $\mathrm{E} 1, \mathrm{C} 1, \mathrm{D} 1, \mathrm{~A} 1, \mathrm{~B} 1$ are $320^{\circ} \mathrm{C}, 350^{\circ} \mathrm{C}$, $355{ }^{\circ} \mathrm{C}, 360{ }^{\circ} \mathrm{C}$ and $365{ }^{\circ} \mathrm{C}$ respectively. Thus, sol gel is the best method of catalyst preparation. The ranking order of the preparation methods of the catalyst in soot oxidation activity is as follows: sol-gel > urea nitrate combustion > Urea gelation method $>$ thermal decomposition $>$ coprecipitation.
Table 3. Comparison of difference in $\mathrm{T}_{1 / 2}$ for fresh and aged catalysts

\begin{tabular}{cccc}
\hline Catalyst & \multicolumn{2}{c}{$\mathrm{T}_{1 / 2}\left({ }^{0} \mathrm{C}\right)$} & $\Delta \mathrm{T}_{1 / 2}\left({ }^{0} \mathrm{C}\right)$ \\
\cline { 2 - 3 } & Fresh & Aged & \\
\hline $\mathrm{A}$ & 360 & 380 & 20 \\
$\mathrm{~B}$ & 365 & 400 & 35 \\
$\mathrm{C}$ & 350 & 370 & 20 \\
$\mathrm{D}$ & 355 & 375 & 20 \\
$\mathrm{E}$ & 320 & 325 & 5 \\
\hline
\end{tabular}

\subsection{Effect of preparation methods on stability}

The activity of the catalysts after ageing at $800{ }^{\circ} \mathrm{C}$ for $4 \mathrm{~h}$ was investigated and the effect of various methods of preparation on stability of the samples for soot oxidation is shown in Figure 4. Aged catalyst, E2 showed the best activity among the five samples. A similar trend can be visualized in the case of ageing also as the case of effect of preparation methods on the activity of fresh catalysts. The trend is clearer on comparison of difference in $\mathrm{T} 1 / 2$ for fresh and aged catalysts as shown in Table 3 . The difference in T1/2 for fresh and aged catalysts prepared by sol-gel method is just $5{ }^{\circ} \mathrm{C}$ while this value is 35 ${ }^{0} \mathrm{C}$ for co-precipitation method. Ageing effect on catalyst B2 is more pronounced than others. After ageing, the segregated $\mathrm{CuO}$ clusters sintered for catalyst prepared by co-precipitation method (B2) while highly dispersed $\mathrm{CuO}$ in catalyst resulted by sol-gel method (E2) is prevented from sintering on ageing to a great extent. This statement is in accordance with the data of particle size analysis of fresh and aged catalysts reported in table 2 . It is clear that the average particle size, $2.13 \mu \mathrm{m}$ of aged catalyst (B2) prepared by co-precipitation method sintered to a larger extent (1.06 $\mu \mathrm{m}$ for fresh B1) than for catalyst (E2) prepared by solgel method $(0.93 \mu \mathrm{m}$ for fresh $\mathrm{E} 1$ and $1.29 \mu \mathrm{m}$ for aged E2). Ceria is more refractory to copper oxide hence sol-gel method resulted highly dispersed $\mathrm{CuO}$ in the catalyst and prevented sintering than catalysts produced by other methods.

Thus, sol-gel is the excellent method of catalyst preparation showing the best performance for diesel soot oxidation in comparison to the other methods of preparation studied in the present investigation. The ranking order of the preparation methods of the catalyst in soot oxidation performance (activity and stability) is as follows: sol-gel > urea nitrate combustion $>$ Urea gelation method $>$ thermal 
decomposition > co-precipitation.

\section{Conclusions}

The catalytic performance of $\mathrm{CuO}-\mathrm{CeO}_{2}$ catalysts strongly depends upon preparation method for the selective soot oxidation. The catalysts prepared by sol gel method showed the best catalytic performance, this is ascribed to uniform dispersion of copper species in the catalyst. The catalyst sample prepared by coprecipitation method presents lowest performance may be due to bulk segregated formation of $\mathrm{CuO}$ in the sample.

The ranking order of the preparation methods of the catalyst in soot oxidation performance is as follows: sol-gel $>$ urea nitrate combustion $>$ Urea gelation method $>$ thermal decomposition $>$ co-precipitation.

\section{Acknowledgements}

The authors gratefully acknowledge the utilization of instruments and equipments received from the Department of Science \& Technology, Government of India, under the SERC (Engg. Science) Project Grant NO.SR/S3/ME/ 027/2006. The authors are grateful to Dr A.S.K. Sinha for his help in carrying out particle size analysis.

\section{References}

[1] Van Setten, B. A. A. L.; Makkee, M.; and Moulijn, J. A. 2001. Science and technology of catalytic diesel particulate filters. Catalysis Reviews 43: 489-564.

[2] Neeft, J. P. A.; Makkee, M.; and Moulijn, J. A. 1996. Diesel particulate emission control. Fuel Processing Technology 47: 1-69.

[3] Fino, D.; Fino, P.; Saracco, G.; and Specchia, V. 2003. Studies on kinetics and reactions mechanism of $\mathrm{La}_{2-\mathrm{x}} \mathrm{K}_{\mathrm{x}} \mathrm{Cu}_{1-\mathrm{y}} \mathrm{V}_{\mathrm{y}} \mathrm{O}_{4}$ layered perovskites for the combined removal of diesel particulate and Nox. Appl. Catal. B 43: 243-259.

[4] Pisarello, M. L.; Milt, V.; Peralta, M. A.; Querini, C. A.; and Miro, E. E. 2002. Simultaneous removal of soot and nitrogen oxides from diesel engine exhausts. Catal. Today 75: 465-470.

[5] Neeft, J. P. A.; Schiper, W.; Makkee, M.; and Moulijn, J. A. 1997. Feasibility Study towards a $\mathrm{Cu} / \mathrm{K} / \mathrm{Mo} /(\mathrm{Cl})$ soot Oxidation Catalyst for Application in Diesel Exhaust Gases. Appl Catal B 11: 365-382.
[6] Uchisawa, J. O.; Obuchi, A.; Wang, S.; Nanba, T.; and Ohi, A. 2003. Catalytic performance of $\mathrm{Pt} / \mathrm{MOx}$ loaded over SiC-DPF for soot oxidation. Appl. Catal. B 43: 117129.

[7] Uchisawa, J. O.; Wang, S.; Nanba, T.; Ohi, A.; and Obuchi, A. 2003. Improvement of Pt catalyst for soot oxidation using mixed oxide as a support. Appl. Catal. B 44: 207-215.

[8] Hinot, K.; Burtscher, H.; Webe, A. P.; and Kasper, G. 2007. The effect of the contact between platinum and soot particles on the catalytic oxidation of soot deposits on a diesel particle filter. Appl. Catal. B 71: 271-278.

[9] Teraoka, Y.; Kanada, K.; and Kagawa, S. 2001. Synthesis of La-K-Mn-O perovskitetype oxides and their catalytic property for simultaneous removal of NOx and diesel soot particulates. Appl. Catal. B 34: 73-78.

[10] Peng, X.; Lin, H.; Shangguan, W.; and Huang, Z. 2007. A highly efficient and porous catalyst for simultaneous removal of $\mathrm{NO}_{\mathrm{x}}$ and diesel soot. Catal. Commun.8: 157-161.

[11] Shangguan, W. F.; Teraoka, Y.; and Kagawa, S. 1998. Promotion effect of potassium on the catalytic property of $\mathrm{CuFe}_{2} \mathrm{O}_{4}$ for the simultaneous removal of NOx and diesel soot particulate. Appl. Catal. B 16: 149-154.

[12] Liu, J.; Zhao, Zh.; Xu, Ch. M.; Duan, A. J.; Zhu, L.; and Wang, X. Zh. 2005. Diesel soot oxidation over supported vanadium oxide and K-promoted vanadium oxide catalysts. Appl Catal B 61: 36-46.

[13] Zhu, L.; Wang, X. Zh.; Yu, J .J.; and Hao, Z. P. 2005. Catalytic performance of $\mathrm{K}$ $\mathrm{Ce}_{0.5} \mathrm{Zr}_{0.5} \mathrm{O}_{2}$ catalysts for soot combustion. Acta Phy-Chim Sin 21: 840-845.

[14] Tikhomirov, K.; Krocher, O.; Elsener, M.; and Wokaun, A. 2006. $\mathrm{MnO}_{\mathrm{x}}-\mathrm{CeO}_{2}$ mixed oxides for the low-temperature oxidation of diesel soot. Appl Catal B 64: 72-78.

[15] Reddy, B. M.; and Rao, K. N. 2009. Copper promoted ceria-zirconia based bimetallic catalysts for low temperature soot oxidation. Catalysis Commun 10: 1350-1353

[16] Castoldi, L.; Matarrese, R.; Lietti, L.; and Forzatti, P. 2006. Simultaneous removal of NOx and soot on $\mathrm{Pt}-\mathrm{Ba} / \mathrm{Al}_{2} \mathrm{O}_{3}$ NSR catalysts. Appl. Catal. B 64: 25-34

[17] Matarrese, R.; Castoldi, L.; Lietti, L.; and Forzatti, P. 2007. High performances of Pt$\mathrm{K} / \mathrm{Al}_{2} \mathrm{O}_{3}$ versus $\mathrm{Pt}-\mathrm{Ba} / \mathrm{Al}_{2} \mathrm{O}_{3}$ LNT catalysts in 
the simultaneous removal of NOx and soot. Top. Catal. 42-43: 293-297.

[18] Lo pez-Sua rez, F. E.; Bueno-Lo pez, A.; and Illan-Go mez M. J. 2008. Cu/Al2O3 catalysts for soot oxidation: Copper loading effect. Appl.Catal. B 84: 651-658

[19] Fua, M.; Yuea, X.; Yea, D.; Ouyanga, J.; Huanga, B.; Wua, J.; and Liangc, H. 2010. Soot oxidation via $\mathrm{CuO}$ doped $\mathrm{CeO}_{2}$ catalysts prepared using coprecipitation and citrate acid complex-combustion synthesis. Catal. Today available online.

[20] Liang, Q.; Wu, X.; Weng, D.; and Lu, Z. 2008. Selective oxidation of soot over $\mathrm{Cu}$ doped ceria/ceria-zirconia catalysts. Catal. Commun. 9: 202-206

[21] Harrison, P. G.; Ball, I. K.; Daniell, W.; Lukinskas, P.; Cespedes, M.; Miro, E. E.; and Ulla, M. A. 2003. Cobalt catalysts for the oxidation of diesel soot particulate. Chem. Eng. J. 95: 47-55.

[22] Liang, Q.; Wu, X.; Weng, D.; and Xu, H. 2008. Oxygen activation on $\mathrm{Cu} / \mathrm{Mn}$-Ce mixed oxides and the role in diesel soot oxidation. Catal. Today 139:113-118.

[23] Wu, X.; Liang, Q.; Weng, D.; and Lu, Z. 2007. The catalytic activity of $\mathrm{CuO}-\mathrm{CeO} 2$ mixed oxides for diesel soot oxidation with a NO/O 2 mixture. Catal. Commun.8: 2110-2114

[24] Prasad, R.; and Rattan, G. 2010. Preparation Methods and Applications of $\mathrm{CuO}-\mathrm{CeO}_{2}$ Catalysts: A Short Review. Bull. Chem. Reac. Eng. \& Catal. 5: 7-30.
[25] Yue, X; Zhang, X.; Fu, M.; Huang, B.; Liang, $\mathrm{H}$.; and Ye, D. 2009. Effect of SO2 on soot oxidation over $\mathrm{LaO} .8 \mathrm{~K} 0.2 \mathrm{Cu} 0.05 \mathrm{Mn} 0.95 \mathrm{O} 3$ perovskites-type catalyst. Chin. J. Inorg. Chem. 25: 1170-1176.

[26] Avgouropoulos, G.; and Ioannides, T. 2003. Selective $\mathrm{CO}$ oxidation over $\mathrm{CuO}-\mathrm{CeO}_{2}$ catalysts prepared via the urea-nitrate combustion method. Appl. Catal. A 244:155167.

[27] Fu, Q.; Kudriavtseva, S.; Saltsburg, H.; and Flytzani-Stephanopoulos, M. 2003. Gold-ceria catalysts for low-temperature water-gas shift reaction. Chem. Eng. J. 93: 41-53.

[28] Serra, V.; Saracco, G.; Badini, C.; and Specchia, V. 1997. Combustion of carbonaceous materials by $\mathrm{Cu}-\mathrm{K}-\mathrm{V}$ based catalysts: II. Reaction mechanism. Appl. Catal. B 11: 329-346.

[29] Querini, C.; Ulla, M.; Requejo, F.; Soria, J.; Sedran, U.; and Miro, E. 1998. Catalytic combustion of diesel soot particles. Activity and characterization of $\mathrm{Co} / \mathrm{MgO}$ and Co,K/MgO catalysts. Appl. Catal. B 15: 5-19.

[30] Shangguan, W. F.; Teraoke, Y.; and Kagawa, S. 1997. Kinetics of soot-O2, soot-NO and soot$\mathrm{O}_{2}$-NO reactions over spinel-type $\mathrm{CuFe}_{2} \mathrm{O}_{4}$ catalyst. Appl. Catal. B 12: 237-247.

[31] Prasad, R.; and Rattan, G. 2009. Design of a Compact and Versatile Bench Scale Tubular Reactor. Bull. Chem. React. Eng. \& Catal. 4: 5 -9 . 